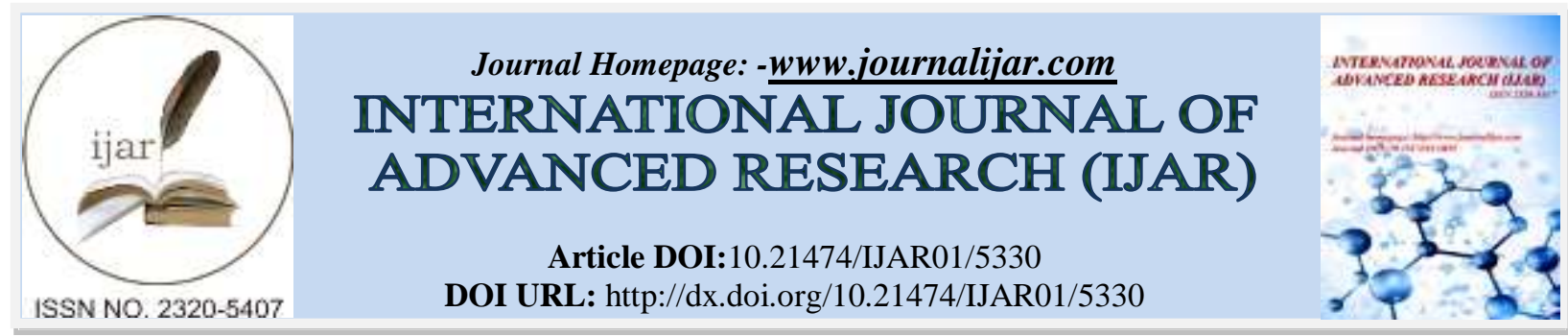

RESEARCH ARTICLE

\title{
SYNTHESIZED ZEOLITE ZSM-5FROM COAL FLY ASH ITS MODIFICATION, HARACTERIZATION AND STUDY OF ITS APPLICATIONS.
}

1. S.G.B. College, Purna-(431511).

Kapure G.P ${ }^{1}$, Shete S.B ${ }^{2}$ and U.D. Joshi².

2. N.S.B.CollegeNanded-(431602).

\section{Manuscript Info}

Manuscript History

Received: 04 July 2017

Final Accepted: 06 August 2017

Published: September 2017

Key words:-

CFA, catalysts, adsorbents, ion conducting, XRD, FTIR, SEM, BET.etc.

\begin{abstract}
Zeolite is synthesized from coal fly ash were attracting huge attention in current era of research because of their uncomplicated, unhazardous synthesis way. The eco-friendly properties have opened a wide field of applications of using these materials in different technologically important fields such as catalysis, adsorption and gas separation. Hence, the commercial zeolite ZSM-5 with their modified forms which were synthesized from coal fly ash is used to test their applications as catalysts, adsorbents and ion conducting materials.

Zeolite synthesized from fly ash is crystalline micro porous aluminosilicates solids containing cavities and channels of a molecular size. The physicochemical properties and the reactivity of the resulting material can vary drastically. The extra-framework species of fly ash aluminosilicates were modified by ion exchange treatments to prepare materials in which transition metal species are well-dispersed, wellmixed and highly accessible to reactants.

In order to obtain a comprehensive picture of morphology, sophisticated analytical techniques were performed by various instrumental methods like XRD, FTIR, SEM, BET surface area analyzer,
\end{abstract}

Copy Right, IJAR, 2017,. All rights reserved.

\section{Introduction:-}

Coal Fly ash (CFA) is a low cost and enthusiastically available Si rich raw material which can be used for reparation of zeolite products. The major components of CFA are silicon oxide $(\mathrm{SiO} 2)$ and aluminum oxide $\left(\mathrm{Al}_{2} \mathrm{O}_{3}\right)$, which are the essential reagents in the synthesis of zeolites ${ }^{1}$.The synthetic zeolites obtained by reprocessing of CFA has huge potential as a cost-effective, eco-friendly solution that can improve the efficiency of these material as efficient heterogeneous catalysts, mainly as solid acids, as adsorbents, and as molecular sieves in gas separation and purification ${ }^{2-4}$. The low price and the additional green benefit (reduced raw materials mining and solid wastes disposal) of the production of zeolites from wastes increase their popularity and inspire growing interest among zeolite researchers and manufacturers worldwide. The primary aim of this research was to use zeolite adsorbents prepared from solid waste residues of coal fly ash, and to demonstrate the feasibility of using this material as catalyst and adsorbent in synthesis of fine chemicals and in purification of contaminated waste water ${ }^{5,6}$.

Corresponding Author:-Kapure G.P. Address:-S.G.B. College, Purna-(431511). 


\section{Modification of Zeolite:}

The modification of zeolite may be carried out during the hydrothermal synthesis. The post synthesis modification can possible by following methods.

\section{Ion Exchange:-}

The presence of aluminum in the silica alumina zeolite framework gives rise to anion, this anion attracts cations in this framework cations are present and they are loosely bounded. The replacement of cation held in the framework structure is possible by the ion present in the external solution. Hence ion exchange is possible.

The rate of degree of cation exchange depends on the following factors:

1) The concentration of the cation exchange solution 2) The Si/Al ratio, 3) Size and charge on cation,

4) Temperature of ion-exchange treatment, 5) Treatment on zeolite before modification, 6) Thermal treatment of zeolite before and after exchange.

\section{Spontaneous Monolayer Dispersion:-}

This method is reported by Xie and Tang ${ }^{4-6}$. Systematic study of series of inorganic salts dispersed on amorphous materials, such as $\mathrm{Gama}-\mathrm{Al}_{2} \mathrm{O}_{3}, \mathrm{SiO}_{2}$, active carbon and $\mathrm{TiO}_{2}$ and found that, the dispersion capacity of the inorganic salts is strongly influenced by the surface area of the amorphous materials at the dispersed temperature. The transition metal oxides having diameters smaller or similar to the channel size of zeolite could disperse into zeolite, while those metal oxides having the diameter larger than channel could not disperse ${ }^{7}$.

\section{Isomorphous Substitution:-}

The replacement of isomorphous elements in crystalline lattice i.e. of elements with similar cationic radii and coordination requirements has also been reported for the synthetic zeolites. When the term isomorphic substitution is used for these compounds, it refers to replacement of T-atoms i.e. Atoms tetrahedral coordinated to oxygen atoms. Commonly encountered $\mathrm{T}$ atoms are silicon and aluminum ${ }^{8-10}$.

\section{De-Alumination of Zeolite:-}

The extraction of tetrahedral coordinated aluminum from a zeolite lattice by acids was first reported by Barrer $^{11}$ etal.framework de-alumination also proceeds upon steaming of $\mathrm{NH}_{4}$ zeolites, as given by Kerr $^{12}$. In 1980, a new dealumination technique based on reaction between silicon tetrachloride and tetrahedral coordinated framework aluminum was reported ${ }^{13}$, 14 . Dealumination of zeolites improves their thermal and catalytic stability. It makes them more efficient in processes such as catalytic cracking or hydro cracking that lead to a rapid deactivation ${ }^{15,16}$. The advantage of using ammonium hexa-fluorosilicate $\left[\left(\mathrm{NH}_{4}\right)_{2} \mathrm{SiF}_{6}\right]$ to de-aluminates zeolites is that, it does not generate extra framework aluminum ${ }^{17,18}$ when zeolites are delaminated by steam calcinations of the framework $\mathrm{Al}$ is extracted and generate extra-framework species that can be cations, anionic or neutral

\section{Choice of the material:-}

Synthetic zeolites when prepared by using pure ingredients are very expensive. Therefore in recent years cheap $\mathrm{Si}$ sources such as CFA which consists predominantly of Si have been used by many workers in synthesis of zeolites $^{19}$ initiated experimenting with the synthesis of zeolites from FA in 1985. The major components of CFA are silicon oxide $\left(\mathrm{SiO}_{2}\right)$ and aluminum oxide $\left(\mathrm{Al}_{2} \mathrm{O}_{3}\right)$, which are the essential reagents in the synthesis of zeolites. Among the many synthetic zeolites and their different properties, in the present work two types of coal fly ash synthesized zeolites such as zeolite ZSM-5 of different framework types are considered because of their wealth of crystallographic knowledge, i.e. chemical composition, aluminum framework sites, cation positions, structural features and the preparation conditions which lead to high ion exchanging, and ion-conducting properties. CFA synthesized zeolite such as, Zeolite ZSM-5 was procured from the Indian Institute of Chemical Technology, Hyderabad.

The procured zeolite ZSM-5 [lattice parameter $\left(a_{0}\right)=20.24 \AA$, $\mathrm{Na}_{2} \mathrm{O}=2.1 \mathrm{wt} \%$ and $\mathrm{Si} / \mathrm{Al}=33$ ], has obtained specific surface area of $423 \mathrm{~m}^{2} / \mathrm{g}$ and has an pore size of $2 \AA$. These zeolites were converted in to their protonic forms which can be used as solid acid catalyst because of the existence of the acid sites of a variable strength in this solids ${ }^{20}$. The protonic forms of the zeolites were further modified by using batch ion exchange method with metal ions like $\mathrm{Zn}^{++}$and $\mathrm{Cd}^{++}$with different metal ion concentrations $(2 \mathrm{wt} \%$, $4 \mathrm{wt} \%$ and $6 \mathrm{wt} \%$ of the metal concentrations). Numerous experimental studies have been carried out in our research work with zeolites modified with $\mathrm{H}^{+}, \mathrm{Cd}{ }^{++}$and $\mathrm{Zn}^{++}$metal ions, such as zeolite catalyzed reductive amination reactions of 
cyclohexanone/cyclohexanol, and as adsorbents in the waste water purifications. Further the effects of the modifications on the conductivity properties of the zeolites were tasted.

\section{Experimental:-}

\section{Post Synthesis Modification of ZSM-5 with $\mathbf{H}^{+}$:-}

Conversion of zeolites in to their protonic form was done by using batch ion exchange method. Zeolite ZSM-5 $(\mathrm{Si} / \mathrm{Al}=33)$ synthesized from fly ash were modified with $\mathrm{H}^{+}$using corresponding acidic salt solutions. Ammonium nitrate $2.5 \mathrm{wt} \%(2 \mathrm{~g})$ was taken in a $250 \mathrm{ml}$ single neck round bottomed flask and to it $30 \mathrm{ml}$ methanol was added as a solvent. Then $10 \mathrm{~g}$ of the dried ZSM-5 powders was added to it and was stirred under reflux condition for $6 \mathrm{~h}$ at 60 0C. Then the mixture was brought to room temperature. After reaching to room temperature the solution was washed repeatedly with double distilled water. The filtered zeolite is $\mathrm{NH}_{4}$ zeolite. It is dried by heating at $110^{\circ} \mathrm{C}$ in an oven for overnight. The $\mathrm{NH}_{4}$ zeolite is heated at $300{ }^{\circ} \mathrm{C}$ in furnace for $4 \mathrm{hrs}$, to drive out ammonia and is converted in $\mathrm{H}^{+}$form. A schematic diagram of the phenomena is depicted in Fig. 1.

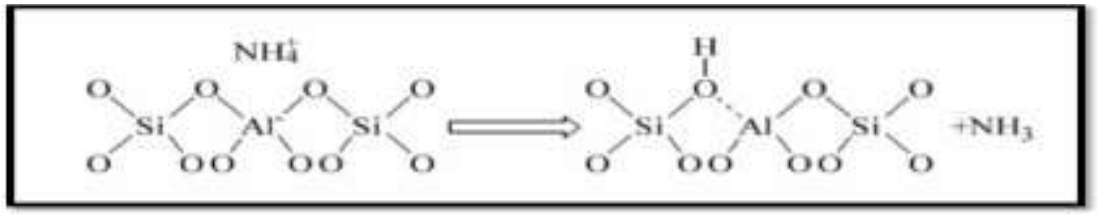

Fig.1:-Schematic diagram of ammonium ions replaced by hydrogen ions

\section{Post Synthesis Modification of HZSM-5 by $\mathrm{Zn}^{++}$and $\mathrm{Cd}^{++}$metal ions:-}

HZSM-5 Zeolite ( $\mathrm{Si} / \mathrm{Al}=33$ ) synthesized from fly ash was modified with transition metal ions like $\mathrm{Cd}++$, and $\mathrm{Zn++}$ using corresponding metal acetate solution as follows: Concentrated salt solutions of $\mathrm{Zn}++$ and $\mathrm{Cd}++\mathrm{metals}(2 \mathrm{wt} \%$, $4 \mathrm{wt} \%$ and $6 \mathrm{wt} \%)$ in their acetate forms were taken in a $250 \mathrm{ml}$ single neck round bottomed flask and to it $30 \mathrm{ml}$ of methanol was added. Then $10 \mathrm{~g}$ of the dried HZSM-5 zeolite powder was added to it and was stirred under reflux condition for $12 \mathrm{~h}$ at $80{ }^{\circ} \mathrm{C}$. Then the mixture was brought to room temperature and solvent was evaporated. The catalyst was dried in the oven at $100{ }^{\circ} \mathrm{C}$, and calcined at $420{ }^{\circ} \mathrm{C}$ or $500{ }^{\circ} \mathrm{C}$ for $4 \mathrm{~h}$ to ensure complete impregnation of the metal ion before use in the reaction. The catalyst was dried in the oven at $100{ }^{0} \mathrm{C}$, andcalcined at $420{ }^{0} \mathrm{C}$ or $500{ }^{0} \mathrm{C}$ for $4 \mathrm{~h}$ to ensure complete impregnation of the metal ion before use in the reaction. These modified forms were named as CdZSM-5, ZnZSM-5, Zeolites. When the concentration of the metal ions in exchange solution varies from $2 \mathrm{wt} \%$ to $6 \mathrm{wt} \%$ of the metal ions, which are named as zeolite name (metal ion concentration) for example ZnZSM$5(2 \mathrm{wt} \%)$.

\section{Characterization, results and discussions:- \\ X-Ray Diffraction (XRD):-}

The X-ray diffraction patterns of HZSM-5 and their modified forms with $\mathrm{Zn}^{++}$and $\mathrm{Cd}^{++}$metal ions are shown in the Figure 2, Figure 4. These XRD patterns were recorded using Siemens Diffract meter, D5000, with CuK $(\lambda=1.54$ A) radiation in the range of $0-50{ }^{0} \mathrm{C}$. The high crystallinity and phase purity of the samples was evidenced by powder XRD. It is observed that intensities and 20values for HZSM-5 is in agreement with the standard XRD data for HZSM-5 and which has the characteristic reflections of the MFI topology. Figure. 3 illustrate that in all the modified forms of HZSM-5 samples, there are marginal changes in the crystallinity after modification with different amounts of $\mathrm{Zn}^{++}$percentage.

The 'd' and the 'hkl' values obtained from XRD are given in Table 1 and are in close agreement with the reported data of ZSM5 zeolite ${ }^{21-22}$. It is observed that there is a shift in d values of the peak corresponding to the (011) plane of modified ZSM-5. This indicates the presence of metal ions in the intracrystalline voids of the ZSM-5 zeolite. Moreover, it is observed that, as the metal ion percentage increases in zeolite the peak intensity also increases, which also indicates that increase of the substitution of transition metals ions.

From the Figure 5 as the metal ions percent increases in modification, there is a decrease in the crystallinity of the samples was observed, hence the modification was stopped at the $6 \mathrm{wt} \%$ of the metal ion concentration to retain the crystallinity of the sample. The crystallinity of the sample was $100 \%$ with the HZSM-5, for 2 wt $\%$ of the metal ion concentration of ZSM-5 it will be $99 \%$ and the gradually decreases up to $86 \%$ for 6 wt $\%$ of the metal ions concentration. The XRD analysis of $\mathrm{Cd}^{++}$modified HZSM-5 were shows similar results and this XRD patterns are shown in the Figure 4 


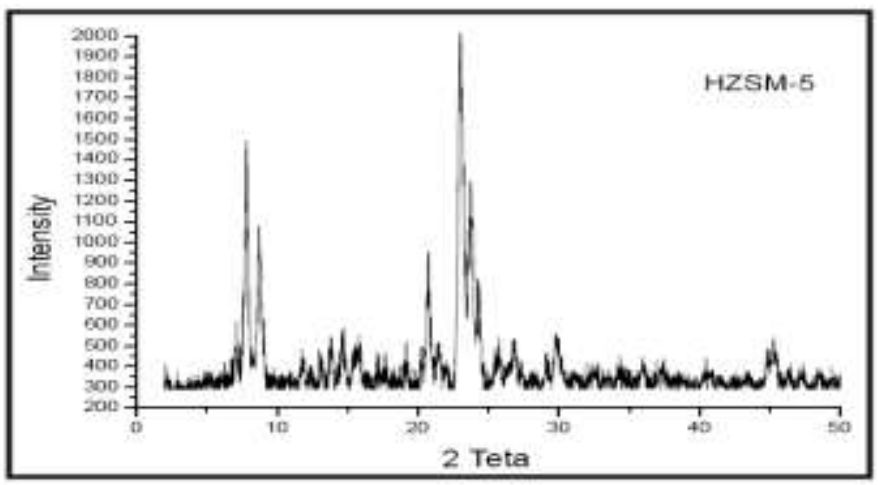

Fig. 2: XRD pattern of zeolite HZSM-5 $(\mathrm{Si} / \mathrm{Al}=33)$

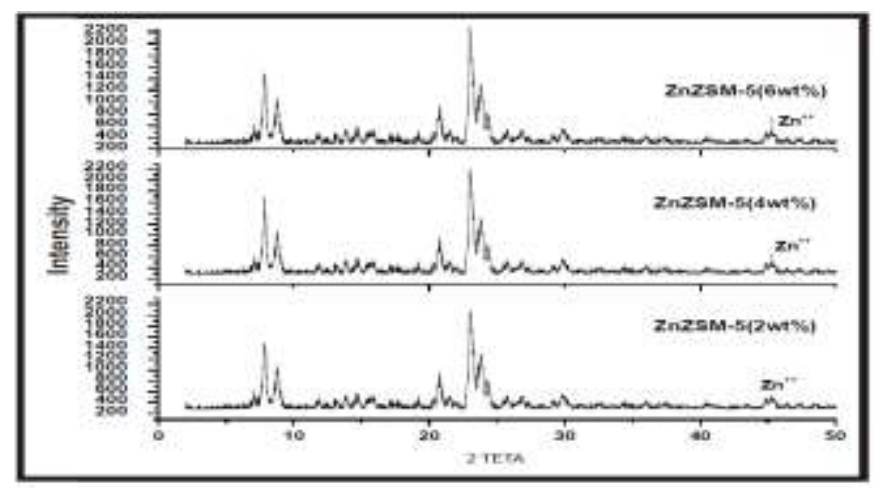

Fig. 3: XRD pattern of ZnZSM-5(2wt\%), ZnZSM-5(4wt \%) and ZnZSM-5(6wt\%)

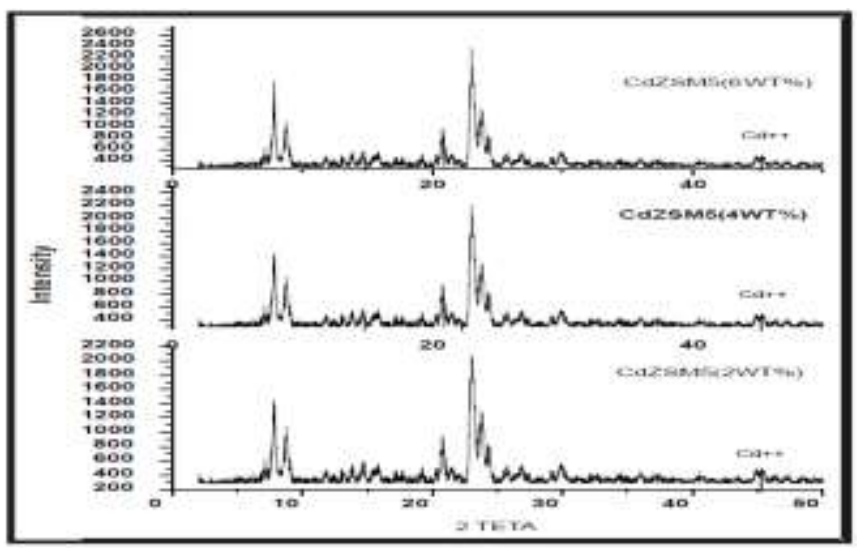

Fig. 4: XRD pattern of CdZSM-5(2wt\%), CdZSM-5(4wt\%) and CdZSM-5(6wt\%) 
Table 1: Comparison of hkl, 20, d, Peak Intensity values (I/I0) of HZSM-5, ZnZSM5 and CdZSM-5

\begin{tabular}{|c|c|c|c|c|c|c|c|c|c|}
\hline \multirow{2}{*}{ bid } & \multicolumn{3}{|c|}{2 -values } & \multicolumn{3}{|c|}{ d-values } & \multirow{2}{*}{$\begin{array}{c}\text { I/16 } \\
\text { H-ZSM } 5\end{array}$} & \multirow{2}{*}{$\begin{array}{c}\mathrm{II}_{0} \\
\mathrm{ZnZSM} 5 \\
\left(4 \mathrm{wra}^{\mathrm{a}}\right)\end{array}$} & \multirow{2}{*}{$\begin{array}{c}\mathrm{II}_{4} \\
\text { Ca ZSM- } \\
\left(4 \mathrm{wro}^{\circ}\right)\end{array}$} \\
\hline & H-ZSM-S & $\begin{array}{l}\text { Zn ZSM-S } \\
\left(4 w t^{6}\right) \text { ) }\end{array}$ & $\begin{array}{l}\text { CaZSMS } \\
(4 w+06)\end{array}$ & H.ZSM-5 & $\begin{array}{c}\text { Zn ZSMS } \\
(4 n+4)\end{array}$ & $\begin{array}{l}\text { Cd ZsM } 5 \\
\left(4 \mathrm{wab}^{4}\right)\end{array}$ & & & \\
\hline 011 & 23.02 & 23 & 23.18 & 3.8422 & 3.8387 & 3.8033 & 100 & 100 & 100 \\
\hline 110 & 29.82 & 25.8 & 25.29 & 3.4781 & 3.4767 & 3.3539 & 14 & 18.08 & 20 \\
\hline 111 & 35.98 & 29.5 & 30.32 & 29502 & 29246 & 3.09905 & 21 & 27,08 & 22 \\
\hline 002 & 32.76 & 35.09 & 32.868 & 2.7314 & 2.7044 & 2.7659 & 07 & 2294 & 19 \\
\hline 020 & 40.54 & 40.52 & 36.18 & 2.4863 & 24584 & 2.4209 & 09 & 6.17 & 04 \\
\hline
\end{tabular}

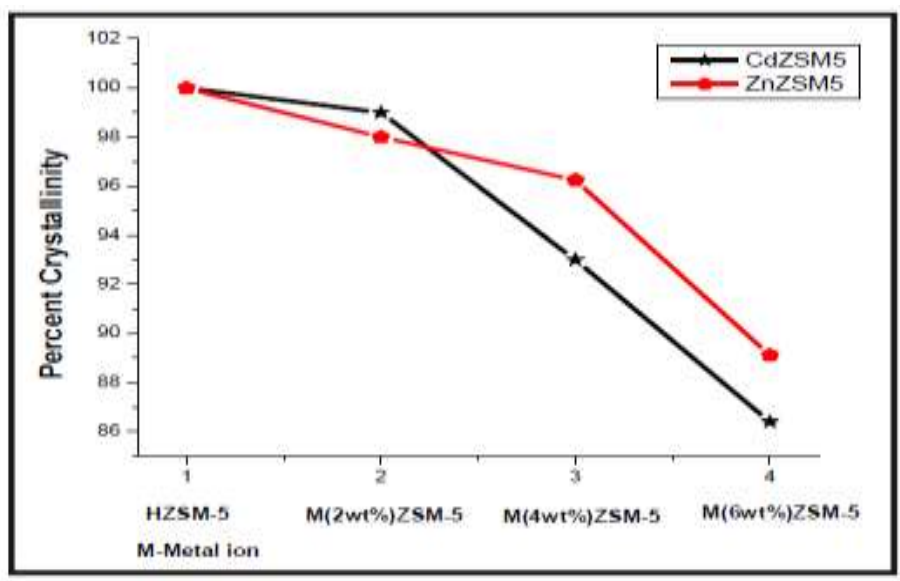

Fig. 5: Effect of the metal concentration on Percent Crystallinity of HZSM-5 Zeolite

\section{Vibrational Spectroscopy (FTIR):-}

Infrared spectra of the zeolites were recorded on the FTIR spectrometer of Nicolet 740 model (USA) in the frequency range of $200-4000 \mathrm{~cm}^{-1}$. In all the zeolite samples the fundamental vibrations of $\mathrm{T}(\mathrm{Si} / \mathrm{Al}) \mathrm{O}_{4}$ tetrahedra of the zeolite framework has been observed in the region 200-1300 $\mathrm{cm}^{-1}$. Figure 6 and Figure 7 show infrared spectra of HZSM-5 and their modified forms with $\mathrm{Zn}^{++}$and $\mathrm{Cd}^{++}$of increasing metal ion percent. In case of HZSM5 it is observed that the structure insensitive asymmetric stretch band is at $1106.5 \mathrm{~cm}^{-1}$. The structure insensitive symmetric stretch band is observed at $800 \mathrm{~cm}^{-1}$. The structure sensitive asymmetric stretch is observed at 1230.44 $\mathrm{cm}^{-1}$. The band near $548 \mathrm{~cm}^{-1}$ is the characteristics of the presence of double five member rings. The infrared spectra of modified HZSM-5 zeolite with $\mathrm{Zn}^{++}$and $\mathrm{Cd}^{++}$shows almost similar pattern. In all these spectrums a sharp band at $546 \mathrm{~cm}^{-1}$ and $550 \mathrm{~cm}^{-1}$ is observed which is the band characteristic of double ring, and is present specifically in ZSM-5 zeolite. There was no change in the peak pattern of the various metal ion exchanged

HZSM-5 zeolites for the $1106.5 \mathrm{~cm}^{-1}$ and $800 \mathrm{~cm}^{-1}$ which are assigned to internal tetrahedron stretching modes, sensitive to the frame work $\mathrm{Si} / \mathrm{Al}$ composition. However, there is an additional peak corresponding to the influence of metal ion were present. This peak is absent in the HZSM-5 sample. As the metal ion percent increases the additional peak is becoming more prominent it conforms the more amount of $\mathrm{Zn}^{++}$and $\mathrm{Cd}^{++}$were incorporated in the mother sample as the concentration of the metal ion increases in the exchange solution. From the infrared spectrum it can be concluded that the structure of the HZSM-5 zeolites was preserved even after the modification of different amounts metal ion concentrations. 


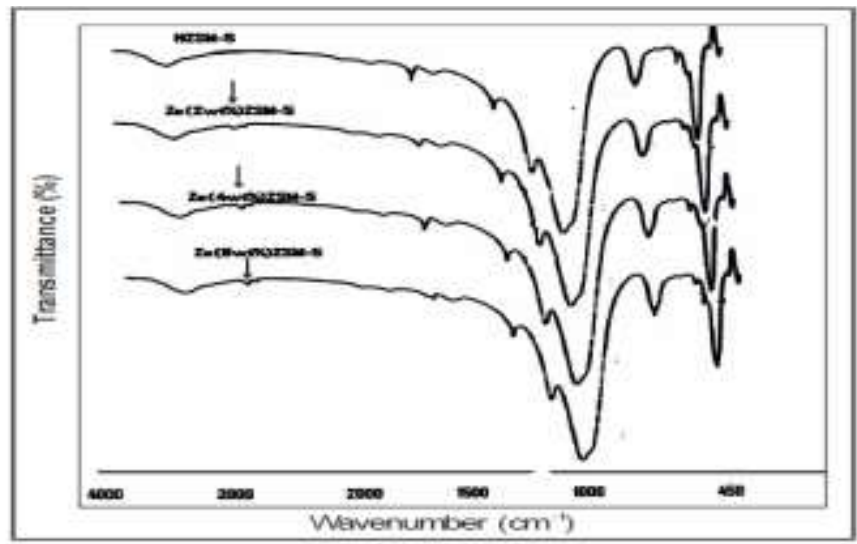

Fig. 6: IR of HZSM-5 and ZnZSM-5 (2wt \%), ZnZSM-5 (4wt \%) and ZnZSM-5 (6wt \%).

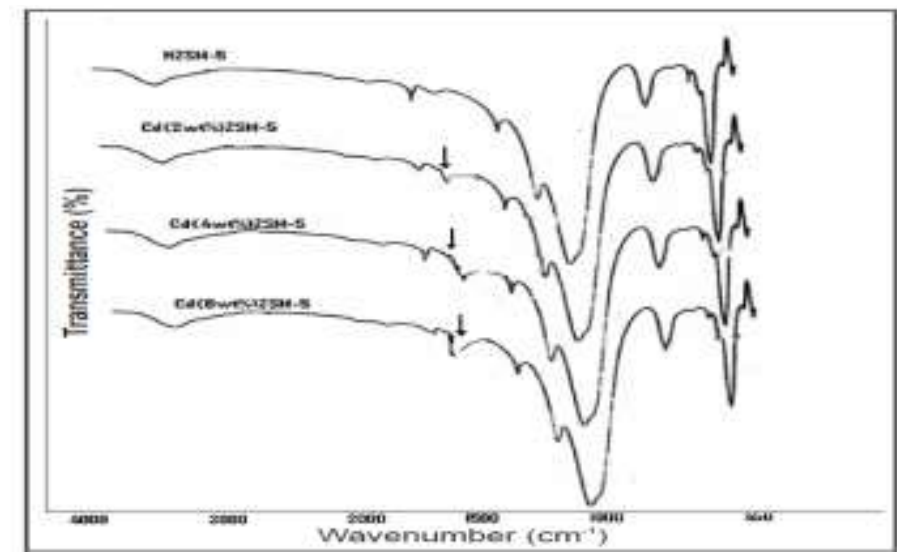

Fig.7: IR of HZSM-5 and Cd ZSM-5 (2wt\%), Cd ZSM-5 (4 wt\%) and Cd ZSM-5 (6wt\%). Scanning Electron Microscopy (SEM):

In the scanning electron microscope (SEM) a very fine 'probe' of electrons with energies up to $40 \mathrm{KeV}$ is focused at the surface of the specimen in the microscope and scanned across it in a pattern of parallel lines. The intensity of emission of both secondary and backscattered electrons is very sensitive to the angle at which the electron beam strikes the surface, i.e. to topographical features on the specimen. The crystallite size and shape is often influenced by different synthesis parameter ${ }^{23-24}$. The silica to alumina ratio, source of silica, source of alumina and tinplating agency influences the crystal morphology ${ }^{25-27}$. Figure 8 illustrates the SEM image of the HZSM-5. The crystallites show two morphologies, such as cubical and spherical habit and majority of them are cubical shaped. The crystallites are of $2 \mu \mathrm{m}$ to $3 \mu \mathrm{m}$ in size. The SEM images of the modified forms of the HZSM-5 with $\mathrm{Zn}^{++}$and Cd ${ }^{++}$ shown in Figure $9(\mathrm{a} \& \mathrm{~b})$ which shows a change in the particle size, but the majority of the particles possess the shape of the cubical.

It is seen that the morphology of the crystals also gets affected as the metal ion percent gradually increased. The SEM photograph of HZSM-5 sample shows bigger crystal size while the modified forms with $4 \mathrm{wt} \%$ of the metal ions have decreased crystal size which may affect the surface properties of the zeolites which tend to use the zeolites for different applications. 


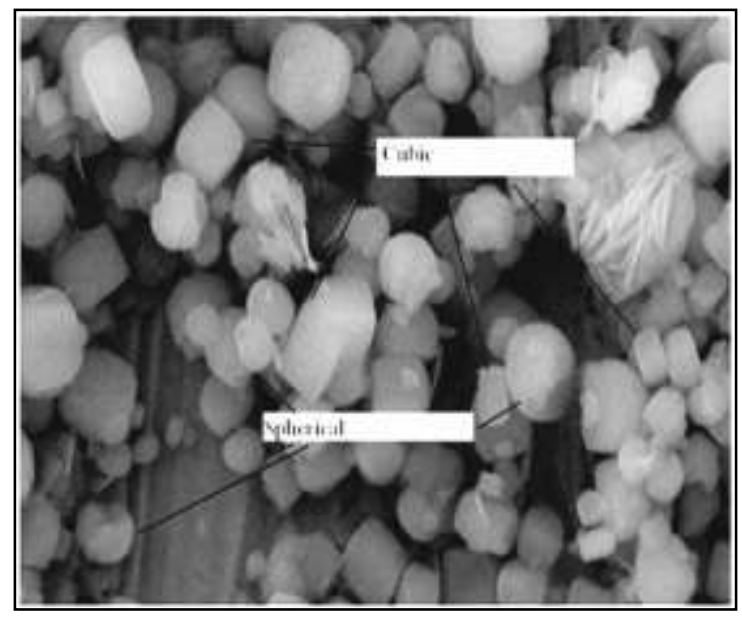

Fig. 8:-SEM image of HZSM-5
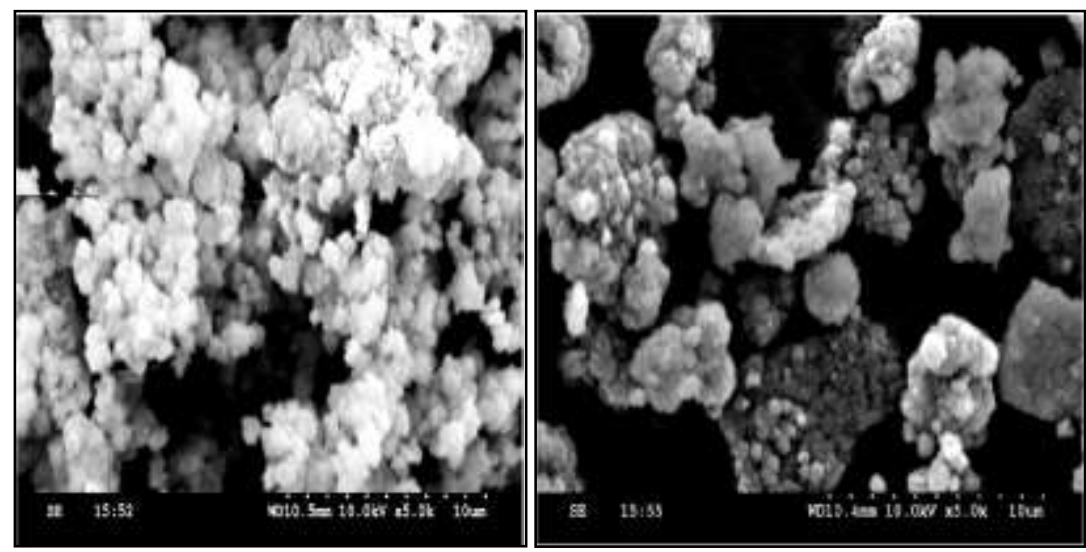

Fig. 9 (a) and 2.15 (b):-SEM images Zn ZSM-5 (4wt\%) Cd ZSM-5 (4wt\%).

\section{BET surface areas:-}

The specific surface area of the catalyst was carried out by using Auto Chem 2910 (Micrometrics) using $\mathrm{N}_{2}$ adsorption at $196{ }^{\circ} \mathrm{C}$ by the single point BET method taking $0.0162 \mathrm{~nm}$ as its cross sectional area. The surface area of HZSM-5 and $\mathrm{Zn}^{++}$and Cd ${ }^{++}$modified HZSM-5 is given in Table 2. The surface area of the HZSM-5 is of the order of $423 \mathrm{~m}^{2} / \mathrm{g}$. From the table it is evident that the surface area of the metal substituted HZSM-5 decreases as compared to its un-substituted counterpart. There is a reduction of surface area and pore volume of zeolites on inclusion of metal ions. Since the zeolite framework structure is not affected by modification which also illustrated by the XRD patterns, the reduction of surface area and pore volume provides direct evidence of the presence of transition metal ions in the cavities.

Table 2:-BET surface area and pore volume HZSM-5 Zeolite modified with $\mathrm{Zn}^{++}$and $\mathrm{Cd}^{++}$

\begin{tabular}{|l|l|c|c|}
\hline S.No. & Catalyst & Pore Volume $\mathbf{~ c m}^{-\mathbf{3}} \mathbf{g}^{-1}$ & Surface Area $\mathbf{~ m}^{\mathbf{2}} / \mathbf{g}$ \\
\hline $\mathbf{1}$ & HZSM-5 & 0.2 & 423 \\
\hline $\mathbf{2}$ & ZnZSM-5 (2wt \%) & 0.2 & 419 \\
\hline $\mathbf{3}$ & ZnZSM-5 (4wt \%) & 0.17 & 401 \\
\hline $\mathbf{4}$ & ZnZSM-5 (6wt \%) & 0.15 & 393 \\
\hline $\mathbf{5}$ & CdZSM-5 (2wt \%) & 0.2 & 400 \\
\hline $\mathbf{6}$ & CdZSM-5 (4wt \%) & 0.13 & 394 \\
\hline $\mathbf{7}$ & CdZSM-5 (6wt \%) & 0.11 & 382 \\
\hline
\end{tabular}




\section{Summery and Conclusion:-}

Zeolites have been used for the preparation of fine chemicals. Most of the work in literature has disclosed that zeolites could be effectively utilized as catalysts and adsorbents for many organic transformations and environment friendly processes. The scope of the paper is to study the modification, characterization of the fly ash synthesized zeolites for better understanding of their behavior as adsorbents, catalysts, and ion conducting materials. We have reported a systematic study of a series of transition metal ions exchanged ZSM-5 zeolites prepared by coal fly ash, their physico-chemical properties for adsorbent activity in waste water purifications, ion conducting behavior, which can supports these material as the next generation materials with environmental concerns. The catalytic activity of these materials for vapor phase reductive amination of Cyclohexanone/Cyclohexanol was reported. The exchanged zeolites are characterized by XRD, IR, SEM, BET surface area etc. The extent of crystallinity of these samples was obtained from the powder XRD patterns recorded over the range $0<2<500$. The decrease in the intensity in the Xray patterns with ion exchange is attributed to the distortion of the framework due to the presence of highly polarizable transition metal ions.

XRD of all the samples were matching with standard material. All the samples were highly crystalline even after modification. FTIR analysis showed that the basic zeolite structure is preserved during ion exchange. In the FTIR spectra of metal substituted catalyst a band at $960 \mathrm{~cm}^{-1}$ observed. This could be related to metal incorporation into framework positions. This band could be assigned to Si-O-T ( $\mathrm{T}=$ metal ion). SEM pictures show that regular particles with pillow shaped morphology are formed. The morphology of the catalysts is nearly a round ball with uniform crystal size and looks rather similar. From the SEM results, it can be deducted that all these materials show almost complete absence of amorphous material. The surface area was determined from the linear part of BET plot. All the catalysts have shown very good activity towards their ion conducting nature, and also for reactions in the vapor phase.

Effect on the adsorptive behavior of modified zeolites prepared from coal fly ash in treatment of effluent water is studied. Treatment of sugar industrial waste water by using the ion exchange method with fly ash synthesized zeolite HZSM-5 $(\mathrm{Si} / \mathrm{Al}=33)$ was performed. In order to achieve the greatest efficiency of the process and to optimize the degree of removal of contamination during the application of the sorbent material for waste water treatment, effect of type of zeolite adsorbate, the effects of adsorption of the solid to liquid ratio, and effect contact time were investigated.

Further to test the catalytic behavior Protonated, transition metal modified forms of the fly ash prepared Zeolite ZSM-5 ( $\mathrm{Si} / \mathrm{Al}=33)$ were used as catalysts in production of cyclohexanone/cyclohexanol by vapour phase reductive amination reaction. The selectivity for Cyclohexylamine, N-Cyclohexylidene increases from $45 \%$ to $95 \%$. The introduction of $\mathrm{Zn}, \mathrm{Cd}$ on the zeolite surface has a significant effect not only on the cyclohexanone but also on the product distribution. The conversion of cyclohexanone increases with $\mathrm{Zn}$ loading. For example, over zeolite ZSM-5 the conversion increases from $55 \%$ in the absence of $\mathrm{Zn}$ to $65 \%$ on $2 \%$ loading of $\mathrm{Zn}$ which further increases to 80 $\%$ with $6 \%$ loading of $\mathrm{Zn}$. In all the above reactions the final products identified were N-Cyclohexylidene, Cyclohexanone, 2-Cylohexylidene The major product being Cyclohexylamine, $\mathrm{N}$ - Cyclohexylidene. From the experimental data it is observed that zeolite ZSM-5 is more active catalyst for reductive amination reactions.

\section{References:-}

1. Querol, X., Umana, J.C., Plana, F., Alasuey, A., Lopez-Soler, A., Valreo, M.A., Domingo, M.J.andGarcea-Rojo, E.: Synthesis of zeolites from fly ash at Pilot plant scale: Examples of potential applications. Fuel, 80, (2001), p.857-865.

2. P.B.Venuto, E.T. Habib Jr., in: Fluid Catalytic Cracking with Zeolite Catalysts, Marcel Dekker, New York, Basel, (1979), p.156.

3. R.VonBallmoos, D.H. Harris, J.S. Magee, in: G. Ertl, H. Knbzinger, J. Weitkamp (Eds.), Handbook of Heterogeneous Catalysis, Vol. 4, Wiley-VCH, Weinheim, (1997), p. 1955.

4. Holler, H. and Wirsching, U.: Zeolite formation from fly ash. FortschritteMineralogie, 63, (1985), p 21-43

5. Querol, X., Moreno, N., Umana, J.C., Alastuey, A., Hernadez, E., Lopez- Soler, A. and Plana, A.: Synthesis of zeolites from coal fly ash: an overview. International Journal of Coal Geology, 50, (2002), p. 413-423.

6. Moreno, N., Querol, X. and Ayora, C.: Utilisation of zeolites synthesised from coal fly ash for the purification of acid mine waters. Environmental Science and Technology, 35 (2001), p. 3526-3534,

7. W. Lowenstein, Am. Mineralogist 39 (1954). 
8. U.D. Joshi, P.N. Joshi, S.S. Tamhankar, V.V. Joshi, C.V. Rode, V.P.Shiralkar, "Effect of non frameworkcations and crystallinity on the basicity of NaX Zeolite", Applied Catalysis A: Elsevier Science. UK, 239/1-2, p. 209220.

9. Ch. Baerlocher, W.M. Meier, D.H. Olson, Atlas of Zeolite Framework Type,5th ed., Elsevier, Amsterdam (2001).

10. W.M. Meier and D.H.Olson, Atlas of Zeolite Structure Types, 3rd ed. Butterworth -Heinemann, London (1992).

11. Barthomeuf, D. Catal. Rev. 38, (1996), p.521.

12. Joshi U.D., P.N. Joshi, S.S. Tamhankar, V.P. Joshi, B.B. Idage, V.V. Joshi and V.P. Shiralkar, "Influence of the size of extraframework monovalent cation exchange in X-type zeolite on their thermal behavior," Thermochimica Acta,387, 121-130, 2002 (Elsevier Science, UK)

13. Corma, A. J. Catal. 216, (2003), p. 298.

14. Lim, W.T.; Choi, S.Y.; Choi, J.H.; Kim, Y.H.; Heo, N.H.; Seff, K. Microporous and Mesoporous Mater. 93, (2006), p.234.

15. A.F. Cronstedt, KonglVentenskpsAcad. Handl. Stockholm, 18 (1756), p. 120-130.

16. Flanigen E M, in "Introduction to Zeolite Science and Practice" (Van Bekkum H, Flanigen E M, Jansen J C, eds), Stud. Surf. Sci. Catal. 58, (1991), p. 13.

17. Breck D W, “Zeolite Molecular Sieves”, Krieger, Malabar (Florida) (1984).

18. Perego G, Millini R, Bellussi G, in Molecular Sieves (Karge H G, Weitkamp J, eds.), 1, (1998), p. 188.

19. R.M. Barrer, Pure and App. chem. 51 (1957), p. 1091

20. J.W.Mc Bain, "The Sorption of gases and vapors by Solids" chap. 5, Rutledge and sons, London (1932).

21. Sugi, Y. and Kubota, Y., Catalysis 13, (1997), p. 55.

22. Mravec, D., Chylík, J., Michvocík, M., Hronec, M., Smiešková, A., and Hudec, P., Chem. Pap. 52, (1998), p. 218.

23. Szostak, R.: Handbook of molecular sieves. New York: Van Nostrand Reinhold (1992).

24. Breck D W, "Zeolite Molecular Sieves, Chemistry and Use", Published by Wiley-Interscience, New York, (1974).

25. M. Guisnet, J. P. Gilson, Zeolites for Cleaner Technologies Imperial College Press, London, (2002).

26. Minerals Yearbook: Volume I. Metals and Minerals: Zeolites, (2008).

27. J. Weitkamp, L. Puppe Catalysis and zeolites: fundamentals and applications. Springer-Verlag, Berlin, (1999).

28. Frilette V J, Haag W O, Lego R M, J. Catal. 67, (1981), p. 218. 